\section{LINES. A BRIEF HISTORY}

Tim Ingold ${ }^{1}$

Routledge 2007 (primera edición); 2010

(reimpresión), ISBN 978-0-415-42427-1

Comentario de Luis Iturra Muñoz ${ }^{2}$

Mientras escribo este texto, cada una de las letras que componen las palabras van apareciendo una a una, sin embargo, mientras usted lee, lo verbal subyacente en el mensaje se va construyendo como un continuo.

Hubo un periodo en el cual la aparición del mensaje y la construcción del texto se movían a la misma velocidad, un periodo en el cual la escritura no era la transcripción técnica de lo verbal, sino más

1 Phd, Antropólogo. The University of Aberdeen, UK. School of Social Science, Chair in Social Anthropology. Ha publicado, como autor 0 editor, más de una decena de libros, entre los que se puede mencionar: Creativity and cultural improvisation (Oxford, Berg, 2007); The perception of the environment: essays on livelihood, dwelling and skill (London, Routledge, 2000).

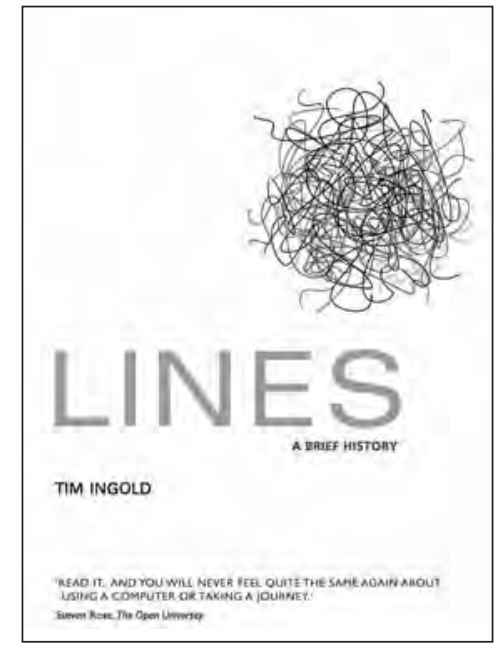

bien, el dibujo de ella era en sí misma el mensaje. Así, cada una de las palabras nacían como dibujos, signos, donde la mano hábil del escritor/dibujante iba plasmando en el paso del tiempo las líneas que paulatinamente iban construyendo lo verbal.

Este camino de la escritura puede ser comprendido como el salto desde la continuidad a la discontinuidad que sufrió la cultura occidental al tratar de comprender y estudiar lo real. Las prácticas

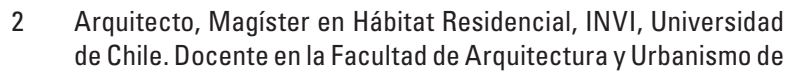
la Universidad de Chile.

revista invi № 76 / Noviembre 2012 / Volumen № 27: 223-226 223 
humanas ya no fueron consideradas como un todo, sino que fue necesario recurrir a la fragmentación de éstas para poder hacerlas operativas y de este modo dominarlas. En el caso de la escritura, esta situación consistió en articular signos cuyo significado propio se encontraba oculto -las letras- y colocarlos, según una serie de normas, en una sucesión que permitiera construir palabras, las cuales serían reconstruidas por el lector para entregar el mensaje.

Habitar, tal como una escritura en el texto urba$n^{3}$, corrió la misma suerte. La existencia humana se vinculó a contenedores de espacio, viviendas, oficinas, salas y así en un sinfín de fragmentos espaciales operativos donde era posible cobijar al ser humano. Las ciencias dejaron de lado el estudio de la continuidad de esa misma vida, la cual era formada en el tiempo y en el espacio, inherente a la existencia humana.

Escribir y habitar, dos prácticas humanas. ¿Qué es lo común entre ellas?. Salir en la búsqueda de aquello común es la motivación del autor de este libro.

El antropólogo Tim Ingold intenta construir, en algo más de 180 páginas y 6 capítulos, lo que él denomina como "una breve historia de la línea", que no es más -ni menos- que la construcción de un viaje para intentar reencontrar aquella continuidad

3 De Certeau, 1996, p. 45. perdida, usando como recurso técnicas de reconstrucción arqueológica, que traen a tiempo presente diversas maneras en las cuales distintas disciplinas se han desarrollado en lo que Ingold describe como "líneas de un tipo u otro".

Lineas. Una breve historia fue publicado por primera vez el año 2007, en inglés, y a la fecha no cuenta con una traducción al español. Con textos que exponen un planteamiento de manera sencilla, el autor nos presenta una serie de escritos donde son comparadas distintas actividades humanas que se han desarrollado a lo largo de "líneas", organizados en capítulos que hacen referencia a una serie de disciplinas o prácticas humanas relacionadas entre sí.

Una aproximación inicial permite leer la intención de Ingold por construir una taxonomía de las líneas, ordenándolas según diversos criterios, pero donde básicamente es posible distinguir dos: los "trazos" -que se relacionan a una superficie-y las "hebras" -que se vinculan a un medio.

Hasta aquí, el libro se asemejaría a la construcción de una abstracción, o un juego teórico, sin embargo, la complejidad del planteamiento de Ingold radica en su vinculación a la cultura material, y por lo mismo, es posible relacionarlo a la construcción física de distintas prácticas humanas, por ejemplo el habitar. El libro no ahonda en el habitar de modo directo, pero es posible leer entre las 
mismas líneas de su construcción, el sentido que cobra el planteamiento al observar otras prácticas humanas. Esta construcción del texto se desarrolla en una estructura por capítulos, los cuales se van conectando entre sí hasta llegar a una conclusión final en el último de ellos. Cada capítulo es acompañado por una cantidad relevante de imágenes e ilustraciones que traen una componente visual a la discusión, permitiendo establecer relaciones con otras disciplinas que utilizan la representación gráfica como medio de construcción de conocimiento, por ejemplo, la arquitectura.

En el primer capítulo, "Lenguaje, música y notación", se establece la relación entre lo hablado y el sonido, es decir, entre la connotación verbal del lenguaje y el sonido de aquel lenguaje. Aquí, Ingold establece una ruta introductoria que parte en el habla y llega al lenguaje escrito de ese habla, no de las palabras, sino de la notación del sonido de las palabras -el escribir como suena- y con esto establecer que la notación es el traspaso de aquello intangible a una superficie en la cual se han formado líneas de algún tipo.

Con esta situación en el aire, el capítulo 2, "Trazos, hebras y superficies", describe y explica la relación que establecen las líneas cuando se vinculan a superficies o a un determinado medio tridimensional. Aparece la vinculación a sistemas de notación en el mundo material, como el tejer. De este modo, las líneas comienzan a perder su velo de abstracción para entrar en la realidad, aparece en este capítulo la relación con el cuerpo.

Siguiendo la idea de esta relación en el mundo material y el cuerpo del ser humano, el capítulo 3, "Arriba, a través y a lo largo", establece la conexión con el lugar, con la forma de comprender las líneas en un territorio donde son desarrolladas prácticas, emergiendo la noción de experiencia y continuidad.

El capítulo 4, "La línea genealógica", toma el camino de la experiencia y lo sitúa en la relación de las líneas y el devenir del tiempo, asociándolo a la idea de crecimiento, a la vinculación de lo pasado con la construcción de lo futuro.

En este punto del libro, Ingold nos lleva a un nuevo planteamiento relacionado con lo que comienza esta reseña, esto es cómo la cultura occidental generó un camino hacia la dominación de la línea. Así, el capítulo 5, "Dibujo, escritura y caligrafía", describe mediante ejemplos el paso cultural desde el dibujo como arte, a la escritura como tecnología; introduciendo aquí el rol de la geometría como despojadora del movimiento que originó la línea, convirtiendo así a lo lineal en una unión de puntos, en una manera de conectar.

A modo de conclusión, el capítulo 6, "Cómo la línea se convirtió en recta", toma este planteamiento, describiendo y analizando la relación de la geometría euclidiana y la concepción de lo lineal. 
Ingold describe y explica cómo en el pensamiento occidental, lo lineal pasó a ser igualado a lo recto. Así se estableció la línea recta como un triunfo de la razón "sobre las vicisitudes del mundo natural".

Si la escritura es la tecnología del dibujo, en la arquitectura tenemos la construcción como tecnología, pero una tecnología ¿de qué? Ingold nos da una pista en otro de sus libros La percepción del ambiente, "No habitamos porque hemos construido, sino que construimos y hemos construido, porque habitamos"4, lo que Heidegger ha mencionado al establecer al habitar como algo más que sólo brindar un alojamiento o una morada ${ }^{5}$.

Lineas. Una breve historia no pretende ser una respuesta o un manual de instrucción de las líneas, verla de ese modo sería reducir el planteamiento a una mera descripción. Lo relevante de este libro está dado por la exposición inteligente y perfectamente documentada de las líneas, como una forma de comprender lo común en diferentes y variadas prácticas humanas. Un cuestionamiento que sólo puede aparecer de interrogar lo habitual, de reconsiderar las conexiones entre lo disímil y volver a armar las piezas de un rompecabezas.

Al final, de eso trata este libro, de armar un rompecabezas, y tal como lo hace Perec ${ }^{6}$, comenzar describiendo las piezas de un juego que el lector va

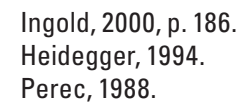

226 revista invi № 76 / Noviembre 2012 / Volumen № 27: 223-226 armando en la lectura, siempre acompañado de la mano hábil de Ingold, con una perspectiva temporal tan vasta que resulta imposible no releer todo, nuevamente, a partir de un puñado de líneas.

\section{Bibliografía}

DE CERTEAU, Michel. La invención de lo cotidiano 1 Artes de hacer. Ciudad de México, México, Universidad Iberoamericana, Departamento de Historia. 1996.

HEIDEGGER, Martin. Conferencias y artículos. Barcelona, España, Ediciones del Serbal. 1994.

INGOLD, Tim. The perception of the environment: essays on livelihood, dwelling and skill. London, UK, Routledge. 2000.

PEREC, Georges. La vida instrucciones de uso. Barcelona, España, Anagrama. 1988. 